E-ISSN :2527-712x

Vol.6 (no.1) Juni 2021

Jurnal Analis Laboratorium Medik

Avalilable Online http://e-journal.sari-mutiara.ac.id/index.php/ALM

DOI: https://doi.org/10.51544/jalm.v6i1.1929

\title{
ANALISA UNSUR HARA MIKRO DARI FLY ASH LIMBAH INDUSTRI PULP DAN KERTAS
}

\author{
Maria Peratenta Sembiring ${ }^{1}$, Chairul $^{1}$, Zulfansyah ${ }^{1}$ \\ ${ }^{1}$ Jurusan Teknik Kimia, Fakultas Teknik, Universitas Riau \\ email: ${ }^{2}$ m_peratenta@yahoo.com
}

Received: Januari 2021; Accepted: April 2021; Published: Juni 2021

\begin{abstract}
The pulp and paper industry continues to grow and produces large amounts of fly ash waste from the biomass combustion process. Alternative waste management besides landfills needs to be developed so that the use of fly ash can be ecologically and economically acceptable, such as for land applications in industrial plantations, especially on peat soils. This paper presents the results of the analysis of micro nutrients from fly ash from pulp and paper mill waste that can be used for agriculture and forestry. The elemental content of boron $(B)$ and zinc $(\mathrm{Zn})$ can be detected in fly ash samples both by lauryl amine extraction and stearyl amine extraction, where the optimum amount is obtained using 15 gram of fatty amine and n-hexane solvent with a processing time of 4 hours. Stearyl amine gives a higher yield than lauryl amine because it has a longer saturated carbon chain.
\end{abstract}

Keywords : Mill waste; waste; pulp and paper; fatty amine; fertilizers, processing.

\begin{abstract}
ABSTRAK
Industri pulp dan kertas terus berkembang dan menghasilkan limbah fly ash dari proses pembakaran biomassa dalam jumlah yang besar. Alternatif pengelolaan limbah selain landfill perlu dikembangkan agar penggunaan fly ash dapat diterima secara ekologis dan ekonomis seperti untuk land application pada hutan tanaman industri khususnya pada tanah gambut. Penelitian ini menyajikan hasil analisa unsur hara mikro dari fly ash limbah pabrik pulp dan kertas yang dapat digunakan untuk pertanian dan kehutanan. Kandungan unsur boron $(B)$ dan seng $(\mathrm{Zn})$ dapat dideteksi pada sampel fly ash baik dengan ekstraksi lauryl amine dan ekstraksi stearyl amine, dimana jumlah optimum diperoleh dengan menggunakan 15 gram fatty amine dengan pelarut n-hexane dengan waktu proses 4 jam. Stearyl amine memberikan hasil lebih tinggi dari lauryl amine karena memiliki rantai karbon yg lebih panjang.
\end{abstract}

Keywords : Limbah; pulp dan kertas; fatty amine; pupuk; pengolahan.

Universitas Sari Mutiara Indonesia DOI 


\section{PENDAHULUAN}

Dalam produksinya industri pulp dan kertasmenghasilkan baik limbah cair dan padat dalam jumlah yang signifikan. Limbah ini harus dikelola dengan cara yang dapat diterima secara ekonomi dan lingkungan. Dalam Sustainability Reportnya (2017) grup APRIL melaporkan bahwa fly ash dan bottom ash adalah produk hasil pembakaran biomasa seperti batubara atau kulit kayu yang merupakan komponen limbah padat yang terbesar hingga $77 \%$. Sebagian besar padatan tersebut dibuang ke tempat pembuangan akhir atau landfill. Dengan semakin terbatas dan mahalnya pembuatan landfill, penelitian pemanfaatan limbah padat perlu diteliti lebih lanjut agar dapat diterima secara ekologis dan ekonomis, diantaranya pemanfaatannya untuk land application pada hutan tanaman industri (HTI) khususnya pada tanah gambut.

Fly ash mengandung unsur-unsur hara yang diperlukan tanaman HTI. Beberapa penelitian menyimpulkan fly ash dapat meningkatkan alkalinitas tanah dengan meningkatkan $\mathrm{pH}$ tanah (Demeyer et al. 2001, Saarsalmi \& Levula, 2007), meningkatkan kualitas tanah termasuk menutrisi, mengkondisikan, dan menyangga tanah yang meningkatkan pertumbuhan dan hasil tanaman (Hatch\& Pepin, 1985; Makela et al., 2010; Muse \& Mitchell,1995; Purwati et al., 2007). Peneliti sebelumnya yang mengekstraksi boron dan seng dari fly ash adalah Oishi et al. (2013) mampu mengekstraksi $30-40 \%$ boron dari coal fly ash dengan asam klorida $(\mathrm{HCl})$ dan Nagib \& Inoue (2000) mampu mengektraksi 19,6$31,2 \%$ seng dari municipal fly ash dengan pelarut alkali

\section{Universitas Sari Mutiara Indonesia DOI}

Unsur hara mikro seperti boron (B) dan seng ( $\mathrm{Zn})$ sering tidak tersedia pada tanah gambut sehingga tanaman menunjukkan gejala kekurangan nutrien ini dan dapat membatasi pertumbuhantanaman walaupun semua unsur hara lainnyatersedia dengan cukup (Mengel, 2001). Boron berperan penting dalam memperkuat dinding sel dan meningkatkan pertumbuhan sel dengan menstimuli proses pembelahan, pendewasaan, dan respirasi sel melalui sintesis RNA yang dibutuhkan (Sutisyoso, 2003; Novizan, 2005). Sedangkan, seng berperan dalam pembentukan hormon IAA (auksin) untuk merangsang pertumbuhan akar tanaman, sebagai katalis yang terlibat dalam kloroplas untuk metabolisme karbohidrat pada proses fotosintesis, serta untuk meningkatkan toleransi tanaman terhadap penyakit (Alloway, 2007; Cakmak \& Engles, 1999).

Etanol adalah pelarut organik yang sangat polar, mudah dibuat dan digunakan sebagai agen alkilasi untuk bereaksi dengan berbagai amina (Han et al. 2018). Sementara n-Heksane adalah pelarut yang mampu mengekstraksi minyak lebih tinggi dari pelarut lain seperti petroleum eter dan etil asetat (Liu\&Mamidipally 2005). Penelitian ini ditujukan untuk menganalisa unsur B dan $\mathrm{Zn}$ pada fly ash dengan mengekstraknya menggunakan fatty amine dengan pelarut alkohol dan n-heksane sehingga penggunaan fly ash pada tanah gambut dapat ditingkatkan dan bermanfaat ganda, yakni menyediakan unsur hara makro dan mikro bagi tanaman. Ekstraksi kandungan unsur hara mikro yang menjadi target adalah unsur B dan $\mathrm{Zn}$ yang dilakukan dengan menggunakan senyawa fatty amine berupa lauryl amine dan stearyl amine dengan pelarut alkohol dan n-heksane 
yang dapat digunakan (Sembiring et al, 2018).

\section{METODE PENELITIAN}

Fly ash dihomogenkan menggunakan saringan ukuran 100 mesh dan ditimbang

Maria Peratenta Sembiring. all| Analisa Unsur Hara Mikro Dari FLY ASH Limbah Industri PULP Dan Kertas sebanyak 50ml dan kemudian di refluks selama 1 jam. Setelah selesai direfluks, larutan di shaker selama 4 jam dan 8 jam.Kemudian didiamkan selama 24 jam sehingga terbentuk 2 lapisan.Lapisan atas dipisahkan dengan menggunakan kertas saring. Lapisan atas ini adalah hasil ekstraksi. Produk ini kemudian dikeringanginkan sambil mengurangi cairan yang masih ada selama 1 jam, kemudian dikeringkan menggunakan oven dengan suhu $100^{\circ} \mathrm{C}$ selama 1 jam.Hasil akhirnya kemudian dianalisa menggunakan Inductively Couple Plasma (ICP) untuk menghitung jumlah unsur B dan $\mathrm{Zn}$ yang ada.
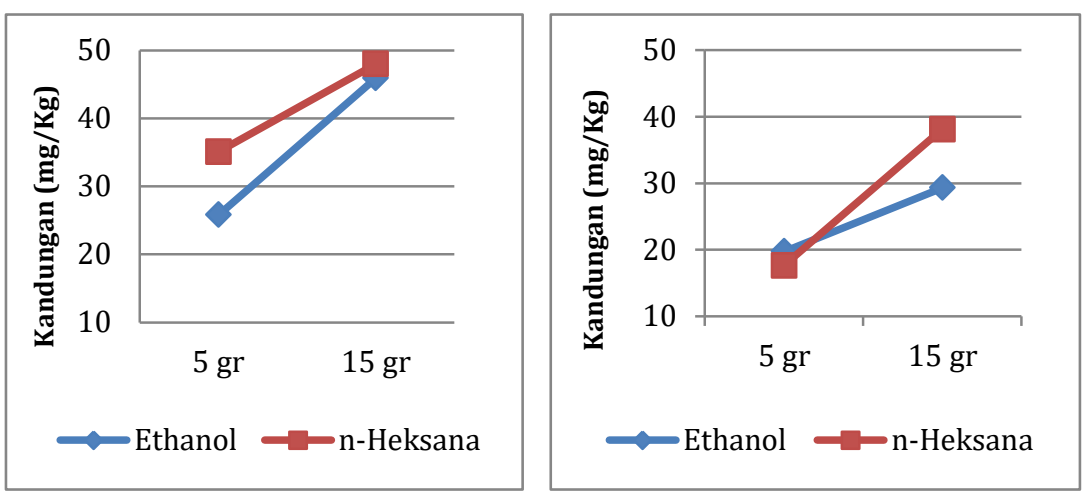

Grafik 1. Kandungan unsur Boron (B) yang diperoleh dengan ekstraksi lauryl amine dengan

\section{HASIL DAN PEMBAHASAN}

Kandungan unsur boron dapat dideteksi pada sampel fly ash baik dengan ekstraksi lauryl amine dan ekstraksi stearyl amine, dimana kandungannya lebih tinggi ketika menggunakan dosis 15 gram dibandingkan 5 gramdengan pelarut n-hexane, dan waktu proses yang terbaik adalah 4 jam. Stearyl amine memberikan hasil yang lebih tinggi daripada lauryl amine karena stearyl aminememiliki rantai non polar yg lebih panjang dan bereaksi dengan baik menggunakan pelarut n-Hexana yang memiliki kepolaran yang lebih kecil daripada etanol.

\footnotetext{
waktu proses 4 jam (kiri) dan 8 jam (kanan)
}

\section{Universitas Sari Mutiara Indonesia DOI}



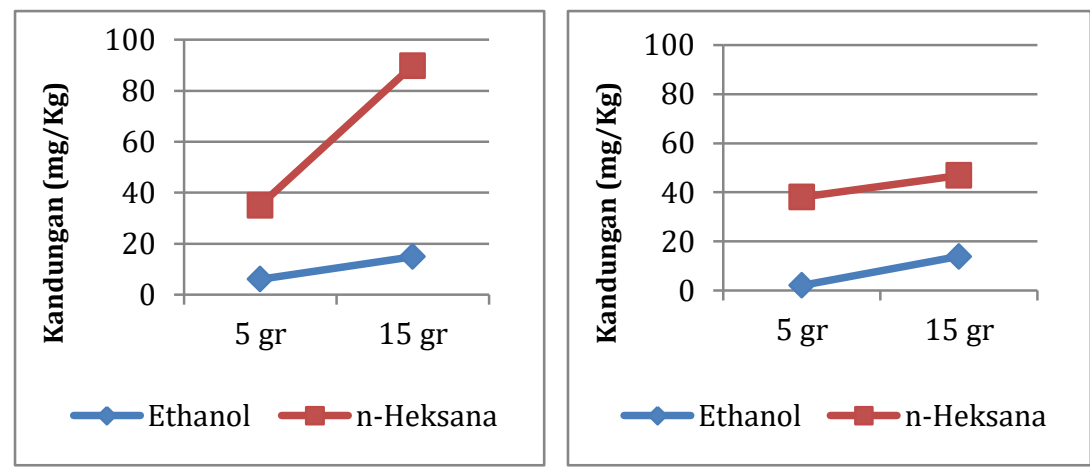

Grafik 2. Kandungan unsur Boron (B) yang diperoleh dengan ekstraksi stearyl amine dengan waktu proses 4 jam (kiri) dan 8 jam (kanan)

Kandungan unsur seng ( $\mathrm{Zn})$ juga dideteksi pada sampel fly ash dengan ekstraksi lauryl amine dan ekstraksi stearyl amine. Sebagaimana hasil ekstraksi kandungan Boron, tren yang sama juga diperoleh dengan kandungan $\mathrm{Zn}$ dimana ekstraksi menggunakan stearyl amine memberikan hasil yang lebih tinggi ketika menggunakan dosis 15 gramdengan pelarut n-hexane dengan waktu proses 4 jam.

Maria Peratenta Sembiring. all | Analisa Unsur Hara Mikro Dari FLY ASH Limbah Industri PULP Dan Kertas
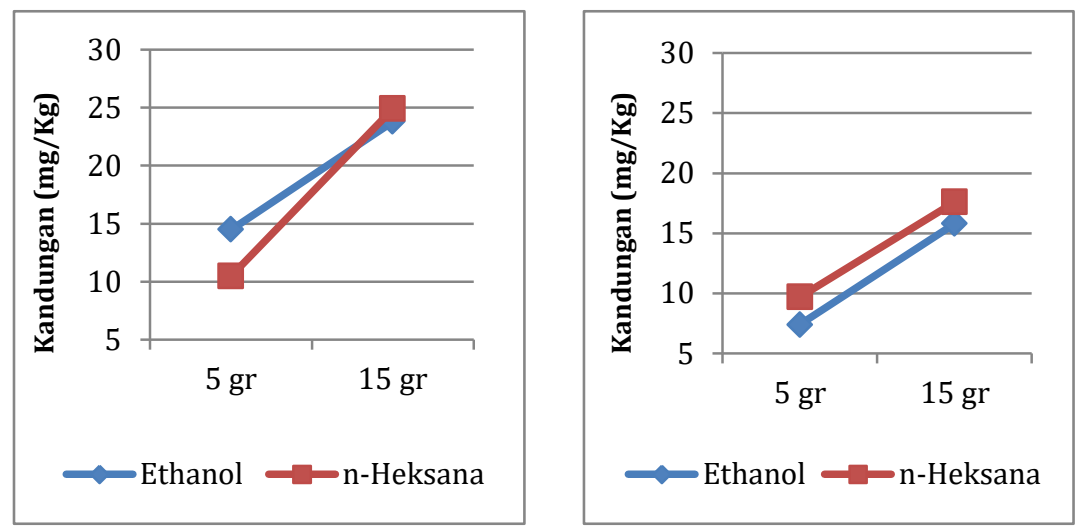

Grafik 3. Kandungan unsur Seng ( $\mathrm{Zn}$ ) yang diperoleh dengan ekstraksi lauryl amine dengan waktu proses 4 jam (kiri) dan 8 jam (kanan).
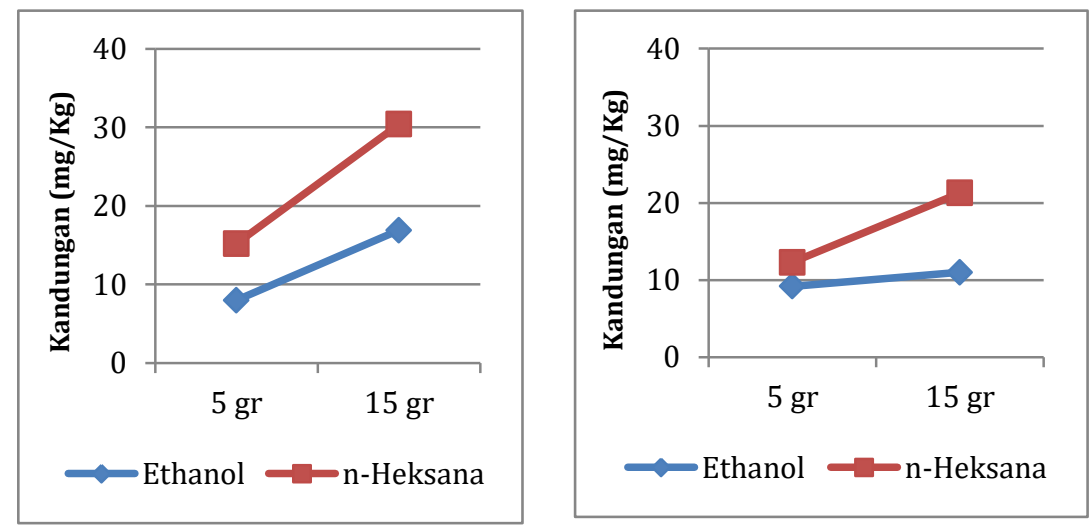

\section{Universitas Sari Mutiara Indonesia}

DOI 
Grafik 4. Kandungan unsur Seng (Zn) yang diperoleh dengan ekstraksi stearyl amine dengan waktu proses 4 jam (kiri) dan 8 jam (kanan)

Dari hasil analisa didapatkan bahwa hasil maksimal diperoleh pada pemakaian stearyl amine dengan menggunakan n-hexana sebagai pelarutnya.Hal ini disebabkan karena polarisitas n-hexane yang lebih kecil dibandingkan etanol, sehingga n-hexane lebih besarkemampuannya untuk melarutkan fly ash yang menggunakan fatty amine yang memiliki rantai carbon yang lebih panjang.

\section{SIMPULAN}

Kandungan unsur boron (B) dan seng (Zn) dapat dideteksi pada sampel fly ash baik dengan ekstraksi lauryl amine dan ekstraksi stearyl amine, dimana jumlah optimum diperoleh dengan menggunakan strearyl amine dosis 15 gram dengan pelarut n-hexane dengan waktu proses 4 jam.

\section{DAFTAR PUSTAKA}

Alloway, B. J. (2008). Zinc in soils and crop nutrition.International Zink Association and International Fertilizer Industry Association, Brussels, Belgium and Paris, France.

Anonim. (2017). Solid Waste Management in Improving Lives APRIL Sustainability Report 2015-2016, pp. 38

Cakmak, I., \& Engels, C. (1999). Role of mineral nutrients in photosynthesis and yield formation. Mineral nutrition of crops: fundamental mechanisms and implications. p. 141168.

\section{Maria Peratenta Sembiring. all | Analisa Unsur Hara Mikro Dari FLY ASH Limbah Industri PULP Dan Kertas}

Han, F., Sun, W., Xia, C. \& Liu, C.(2018). Alcohol as a reagent in homogeneous catalysis, in: Xiao-Feng Wu (Eds.), Solvents as reagents in organic synthesis: reactions and applications. John Wiley \& Sons.535p, pp. 403447.

Hatch, C. J., \& Pepin, R. G. (1985). Recycling mill wastes for agricultural use. Tappi journal, 68(10), 70-73.

Demeyer, A., Nkana, J. V., \& Verloo, M. G. (2001). Characteristics of wood ash and influence on soil properties and nutrient uptake: an overview. Bioresource technology, 77(3), 287-295.

Fukui, T. (2020). An update on the impact of COVID-19 pandemic on the pulp and paper industry in Japan. Appita Magazine, (2), 28.
Liu, K., Wang, H., Liu, H., Nie, S., Du, H., \& Si, C. (2020). COVID-19: Challenges and perspectives for the pulp and paper industry worldwide. BioResources, 15 (3), 4638-4641.

Liu, S. X. \&Mamidipally, P. K. (2005). Quality comparison of rice bran oil extracted with d-limonene and hexane. Cereal Chemistry, 82, 209215.

Mäkelä, M., Watkins, G., Dahl, O., Nurmesniemi, H., \& Pöykiö, R. (2010). Integration of solid residues from the steel and pulp and paper industries for forest soil amendment. Journal of Residuals Science and Technology, 7(4), 191198.

Mengal, K., Kirkby, E. A., Mengal, K., Appel, T., \& Kosegarton, H.

\section{Universitas Sari Mutiara Indonesia DOI}


(2006). Principles of plant nutrition. Springer.

Muse, J. K., \& Mitchell, C. C. (1995). Paper mill boiler ash and lime by-products as soil liming materials. Agronomy Journal, 87(3), 432-438.

Nagib, S., \& Inoue, K. (2000). Recovery of lead and zinc from fly ash generated from municipal incineration plants by means of acid and/or alkaline leaching. Hydrometallurgy, 56(3), 269-292.

Novizan, I. (2002). Petunjuk Pemupukan yang Efektif. AgroMedia Pustaka, Jakarta.

Oishi, K., Maehata, Y., \& Hashino, M. (2013). Simultaneous recovery of boron and other major elements from a coal fly ash by $\mathrm{pH}$ control. Chem. Eng. Process Tech, 1, 109-113.

Purwati, S., Soetopo, R., \& Setiawan, Y. (2017). Potensi penggunaan abu boiler industri pulp dan kertas sebagai bahan pengkondisi tanah gambut pada areal hutan tanaman industri. Jurnal Selulosa, 42(01), 817.

Saarsalmi, A. N. N. A., \& Levula, T. (2007). Wood ash application and liming: effects on soil chemical properties and growth of Scots pine transplants. Baltic Forestry, 13(2), 149-157.

Sembiring, M. P., Kaban, J., Bangun, N., \& Saputra, E. (2018). Use of stearyl amine as a collector of heavy metal from boiler ash in pulp and paper industry. In Journal of Physics: Conference Series (Vol. 1116, No. 4, p. 042032). IOP Publishing.

Sutiyoso, Y. (2003). Меramu pupuk hidroponik: tanaman sayur, tanaman buah, tanaman bunga. Penebar Swadaya. 